\title{
Attachment Security Representations in Institutionalized Children and Children Living with Their Families: Links to Problem Behaviour
}

\author{
Nuno Torres, Joana Maia, Manuela Veríssimo*, Marilia Fernandes and Filipa Silva \\ Unidade de Investigação em Psicologia Cognitiva do Desenvolvimento e da Educação, ISPA-Instituto Universitário, \\ Rua Jardim do Tabaco, Lisboa, Portugal
}

\begin{abstract}
The present work analyses differences in the attachment representations of institutionalized children as compared with children from low and high educational level living with their natural families. Participants were 91 Portuguese children, $52 \%$ girls, aged $48-96$ months. There were three different groups: 19 institutionalized children, 16 low educational level families' children and 56 from high educational level families'. Attachment representations were assessed for Security of the narratives of the Attachment Story Completion Task (ASCT). Psychopathological symptoms were assessed using the Child Behaviour Checklist for parents and caretakers. Verbal skills were assessed using the Wechsler Preschool and Primary Scale of Intelligence-Revised. Results show that institutionalized children have significantly lower security of attachment representations, less verbal skills and higher aggressive behaviour than the other two groups. Attachment representations were associated with social/withdrawal and aggression, independently of age, verbal skills and parents' education. The main effect of institutionalization on externalizing aggressive behaviour was completely mediated by the security of attachment representations. Copyright @ 2011 John Wiley \& Sons, Ltd.
\end{abstract}

Key Practitioner Message:

- Behavior problems, Attachment, Institution.

Keywords: Attachment Representations, Institutionalization, Aggression, Social Withdrawal

\section{INTRODUCTION}

The quality of the early nurturing environment has been considered a main factor in the healthy or pathological development of children's behaviour and cognition, with the majority of researchers stating that a 'good enough' raising environment, susceptible to foster human optimal development, includes a set of typical social parameters and resources, namely protective caregivers, a supportive family background and continued opportunities for exploration (e.g., Cicchetti \& Valentino, 2006; Sroufe, Egeland, Carlson, \& Collins, 2005). In the two last decades of the previous century, acknowledging that threats to the availability of protective reference adults represent suboptimal contexts for normative development, trend in which Bowlby $(1944,1951)$ had been pioneer, researchers started to focus on the relation between individual differences in attachment security and the emergence of psychopathology (e.g., Radke-Yarrow, McCann, DeMulder, \& Belmont, 1995; Weinfield, Sroufe, \& Egeland, 2000).

\footnotetext{
* Correspondence to: Manuela Veríssimo, Unidade de Investigação em Psicologia Cognitiva do Desenvolvimento e da Educação, ISPAInstituto Universitário, Rua Jardim do Tabaco, 34, Lisboa, Portugal. E-mail: mveriss@ispa.pt
}

In what concerns institutionalization, empirical research, both through direct observation of children concurrently in institutions (e.g., Smyke, Koga, Johnson, Fox, Marshall, Nelson, \& Zeanah, 2007; Tizard \& Rees, 1975) and follow-up studies after adoption or foster family placing (Vorria, Papaligoura, Sarafidou, Kopakaki, Dunn, \& Van IJzendoorn, 2006), has stated that, although there is substantial within-group variation, institutional context proves to be a propitious condition for delays in cognitive development, namely, verbal capacities and deficits in social competence, as well as for the increase of psychopathological symptoms, namely, problem behaviours (see Bakermans-Kranenburg, van IJzendoorn, \& Juffer, 2008; MacLean, 2003, for reviews).

One of the original contributions of Bowlby's (1951) report to the World Health Organization was the claim that the causal link between placement at institutions and mental and behaviour problems was the deprivation of maternal love, which he subsequently elaborated as the attachment relationship. So far, substantial evidence was found regarding severe developmental effects due to early exposition to extreme psychosocial and affective deprivation (e.g., Rutter, Colvert, Kreppner, Beckett, Castle, \& Groothues, 2007; Zeanah, Egger, Smyke, Nelson, Fox, \& Marshall, 2009) and the research on Bowlby's 
theoretical proposals has highlighted the link between insecure, disorganized and atypical attachment patterns and children both living at institutions and adopted out of institutions (e.g., Chisolm, 1998; O'Connor, Bredenkamp \& Rutter, 1999; Rutter et al., 2007; Smyke, Dumitrescu \& Zeanah, 2002; Tizard \& Rees, 1975; Zeanah \& Smyke, 2008; Zeanah, Smyke \& Dumitrescu, 2002).

In this exploratory study, we first attempt to infer about the quality of attachment internal working models presented by children between 48 and 96 years of age that are living in different settings-institutionalized children, low educational level families and high educational level families-by comparing attachment-related narratives produced during a story completion task. Knowing that children from adverse social environments may be at increased developmental risk as a result of low economic status (socioeconomic status) and co-variating factors (e.g., superior risk of parental unemployment) which usually go together with a plethora of parental adjustment problems (e.g., greater experienced stress), as discussed by Kobak, Cassidy, Lyons-Ruth, and Ziv (2006), we were also interested to analyse if any impoverishment in attachment representations' security could be found due to parents' lower educational status.

On the second part of the study we focus in the relation between security of attachment representations and three syndromes of externalizing/internalizing problem behaviours-aggressive behaviour, social withdrawal and hyperactivity-in a sub-sample constituted by two groups: institutionalized children and children living with their natural families with equivalent low educational status. In the first case, behaviour problems were reported by the child main institutional caregiver and, in the second case, by the mother. Mediation models were tested to clarify the extent to which the association of institutionalization with the emergence of these syndromes is mediated through attachment representations' security.

\section{Inference of Attachment Internal Working Models Organization through Narratives}

The study of early narratives has been considered to be a possible metaphorical window to children's inner world (Emde, 2003), namely through the use of play doll tasks. Methods such as the MacArthur Story Stem Battery (MSSB) (Bretherton, Oppenheim, Buchsbaum, \& Emde, 1990), the Attachment Doll-Play Interview (Oppenheim, 1997), and the Manchester Attachment Story Task (Green, Stanley, Smith, \& Goldwyn, 2000) have been appointed as valid and promising ways to study mental organization in preschool and school ages.

Inspired by contemporaneous research regarding attachment representations (Cassidy, 1988; Main, Kaplan, \& Cassidy, 1985) and advances in the study of language acquisition, event representation and symbolic play, the
Attachment Story Completion Task (ASCT) (Bretherton \& Ridgeway, 1990), was designed to identify individual differences in the way children enact attachment related situations. The ASCT consists of an interview during which are presented to the child, using a doll family, five-story stems susceptible to activate representational contents linked to safe-base behaviour: child's mishap, pain and fear; separation anxiety; and subsequent family reunion. Individuals are asked to complete each story freely, illustrating the behaviours, emotions and interactions between the characters.

As argued by Bretherton (2005), a central question regarding this type of measures is to know what they actually assess. With most articles preferring to assume that the ASCT evaluates 'attachment representations', a wider, less controversial concept, without specifying if they are referring to working models of early experiences, to representations of current interactions, to more or less complete approaches to secure base scripts [see Waters, Rodrigues, \& Ridgeway, 1998 contribution for a cognitivebased understanding of the relational Internal Working Models (IWMs)], or to generalized models of the relational self not linked to specific figures (e.g., global strategies of relating) this important point is far from being fully answered.

Influenced by Cassidy (1988) and Main et al. (1985), findings in support of the dominance of the interaction with the mother in the construction of the primordial relational IWMs, ASCT authors' first assumption was that the story stems predominantly evoked the operative model of self with the mother. An assumption that was strengthened by Bretherton, Ridgeway, and Cassidy's (1990) seminal studies reporting significant continuity between ASCT security at 37 months and previous and concurrent child-mother attachment behaviour. In addition, ASCT security was predicted by maternal insight/ sensitivity reported in the Parent Attachment Interview, previously created by Bretherton, Biringen, Ridgeway, Maslin, and Sherman, (1989), with links being also found with measures of the child's personality and development and with other family variables reported by mothers.

Since then, the ASCT and adaptations to the procedure, as well to the original coding system, applied at preschool and school ages, has been validated across cultures (e.g., Pierrehumbert, Santelices, Ibáñez, Alberdi, Ongari, \& Roskam, 2009) although more studies are needed to fully confirm the convergent and the discriminant validity of the instrument (Cassibba, Coppola, \& Bruno, 2003;). So far, most studies corroborate the existence of positive associations with children's attachment behaviour towards the mother in infancy (Gloger-Tippelt, Gomille, König, \& Vetter, 2002; Silva, Fernandes, Veríssimo, Shin, Vaughn, \& Bost, 2008; Smeekens, Riksen-Walraven, \& Van-Bakel, 2009) and middle childhood (Solomon, George, \& DeJong, 1995). Links with measures of contemporane- 
ous maternal sensitivity (Goodman, Aber, Berlin, \& Brooks-Gunn, 1998) and with mothers' concurrent, although not past, depressive symptoms have also been found (Trapolini, Ungerer, \& McMahon, 2007). Furthermore, correspondence with the mothers' own attachment representations, assessed with the Adult Attachment Interview (AAI) (George, Kaplan, \& Main, 1984), was reported by Gloger-Tippelt, et al. (2002) and by Miljkovitch, Pierrehumbert, Bretherton, Halfon (2004), with the last study failing to find any type of similar correspondence with the father's AAI.

Moving away from the use of the IWMs concept, an interesting standpoint on this matter was advanced by Oppenheim and Waters (1995) who propose that attachment doll play tasks may mainly assess subjects' capacity to construct and share stories about emotionally charged topics. Authors suggest that what makes secure children to perform better is the repeated experience of emotionally opened communication in the mother-child relationship, crossed by frequent processes of narrative co-construction about significant attachment-related themes. Claiming from the beginning (Bretherton, 1990) that ASCT ratings or classifications should not be treated as equivalent to behavioural attachment measures, Bretherton (2005) welcomes this approach, yet suggesting that it is not incompatible with the idea that this kind of tasks are also assessing internal models of the relational self, reflecting both interpersonal and intrapsychic dynamics, namely defensive processes. Without loosing the idea that children draw on their factual experiences (e.g., attachment related interactions, socialization, mastery episodes, among others) to create the stories Bretherton (2005) adds that adopting an emotional communication perspective can help to understand unrealistic content portrayed in some narratives as meaning-making metaphoric attempts to deal with anxiety-provoking experiences regarding parental accessibility and emotional availability.

\section{Attachment Representations in the Context of Atypical Raising Environments: The Special Case of Institutionalization}

The study of children's mental health determinants raises crucial questions that can only be answered by bringing, atypical attachment behaviour and high-risk raising environments to the forefront of attachment theory and research, as discussed by Waters and Crowell (1999). Undoubtedly, contexts where parents are presently not, or have never been, the primary caregivers (e.g., reconstructed families post-divorce, institutionalization, foster care, adoption at later ages, parental imprisonment, kibbutz) bring complexity to the previous discussed topic, with the effects of disruptive family experiences in the elaboration of attachment representations remaining unclear.

Although researchers have started to apply the ASCT, as well as selections of attachment-relevant story stems from the MSSB, to samples experiencing moderate to high distress, such as parents' divorce (Page \& Bretherton, 2001, 2003), maternal depression (Trapolini et al., 2007), and parental maltreatment (Toth, Cicchetti, Macfie, Rogosch, \& Maughan, 2000), so far, the psychological pathway by which an individual can develop a secure relational self in the context of insecure early relationships is still not fully understood.

Poehlmann (2005) applied the ASCT (once with mother's figure, once with an alternative caregiver doll in a contra-balanced order) to 60 children of imprisoned mothers to find that about two-thirds of the sample tended to construct narratives with clear signs of insecurity. However, giving attention to resilience processes and mechanisms, she also noticed that secure child-mother and child-alternative caregiver representations were fostered by the presence of different protective factors, respectively, not having expressed anger in reaction to the mother's incarceration in the first case, and having expressed sadness in response to the same situation, together with the existence of a stable alternative caregiving situation in the second case. In both applications, older children revealed themselves more prone to show secure representations.

Institutionalization poses greater challenges to the study of attachment representations, as some children have not seen their parents for long years, or never even had a family-raising experience, while others maintain regular or sporadic contact with the biological family. To our knowledge, apart from the Katsurada (2007) exploratory study, no other has used the ASCT with institutionalized children.

\section{Attachment Representations and Behaviour Problems}

Supporting the hypothesized linkages between social behaviour and internal working models of relationships with caregivers, significant associations have consistently been found between representational attachment assessments and broader aspects of children socio-emotional functioning (e.g., Page \& Bretherton, 2001; Solomon et al., 1995; Verschueren \& Marcoen, 1999), although sometimes in contra-intuitive directions (Goldwyn, Stanley, Smith, \& Green, 2000; see also Warren, 2003 for an integrative review).

Giving support to the idea that behaviour draws greatly upon children's inner organization of their life experience, studies with the ASCT highlighted significant associations between ratings of behaviour problems and story 
completions. Examining ASCT's factor structure HubbsTait et al. (1996) reported that the Departure factor, which includes disorganized and insecure responses to parents' departure as well as disorganized narratives focusing children's misbehaviour and fear, possibly reflecting generalized expectations about coping with threat, predicted later externalizing behaviour problems reported by adolescent mothers. Moreover, it was able to discriminate between symptoms in the normative and in the clinical range.

Comparing maltreated and normative preschoolers, Toth et al. (2000) showed a partial mediation effect of conflictual narrative themes on the relation between child maltreatment and externalizing problems reported by teachers. Laible, Carlo, Torquati, and Ontai (2004), found that teacher's ratings of externalizing behaviour were positively associated to the inclusion of aggressive themes, and negatively associated with the inclusion of prosocial themes, as well as with narrative coherence. Scoring 3-year-olds' ASCT narrative features using a Q-set methodology, Miljkovitch, Pierrehumbert, and Halfon (2007) reported that representations of supportive caregiving could predict mother-reported internalizing problems (negative association), even if positive resolution and attachment strategies (security, deactivation, hyperactivation, disorganization) could not. Similar correlational findings have been reported with alternative subsets of the MacArthur Story Stem Batery, as well as alternative doll play measures (Oppenheim, 2003; Oppenheim, Nir, Warren, \& Emde, 1997; Smeekens, et al., 2009) with gender effects sometimes being reported (von Klitzing, Kelsay, Emde, Robinson, \& Schmitz, 2000).

\section{Main Effects Models and Mediation Models}

Fostered by a series of studies of high-risk samples and an understanding of contextual variables that influence caregiving quality and psychopathology, attachment researchers (e.g., Kobak et al., 2006; Sroufe et al. 2005) have moved from simple main effects models of infant attachment insecurity as a predictor of psychopathology to more complex multilevel models of risk. As Deklyen and Greenberg (2008) point out, describing the antecedents of psychopathological symptoms as if they were either pure personal attributes of the child (e.g., IWM) or pure environment impingements (e.g., atypical and sub-optimal caregiving), seems insufficient to understand the equifinality and multifinality dynamics of symptom formation along development. In fact, although insecure and disorganized attachment with caregivers represent risk factors for a wide variety of disorders, there is no clear association between classifications and specific psychiatric sequelae (see Zeanah and Smyke, 2008), being needed a more accurate estimation of the relative contribution of attachment and caregiving processes to the emergence of psychopathology.
An attachment-based framework for research that takes into account multiple levels of analysis in the determination of deviant developmental trajectories was proposed by Kobak et al. (2006). These authors have proposed that research on attachment and psychopathology can be cleared if framed by three levels of analysis, in which the degree of risk may vary: (1) individual organization of attachment; (2) caregiving quality; and (3) caregiving context. Applying this framework to the study of institutionalized children, the atypical caregiving quality and the extreme attachment disruptions may substantially increase the risk for the emergence of psychopathology directly and/or by contributing to the insecurity and disorganization of attachment organization. In the present state of affairs, as long as they are able to include symptom outcomes and assess the extent to which the effect of one level of analysis (e.g., environmental context-institutionalization) on outcomes is mediated through a second level of analysis (e.g., organization of attachment internal models), mediation models seem to provide a better way of distinguishing between attachment- and nonattachment-related risk for behaviour problems.

With respect to the above presented discussion, we stated the following hypothesis:

1. Even after controlling for language differential capacities, the narratives of institutionalized children were expected to be less secure than the ones produced by family-raised children.

2. Although of smaller dimension, we also predicted differences between the two family-raised groups, with the parents' high educational status children expecting to perform better at the ASCT.

3. Institutionalized children were expected to evidence more behavioural problems than children living with their natural families with equivalent low educational status.

4. Insecure and disorganized narrative representations were expected to be positively correlated with childreported behaviour problems in both samples.

5. A mediation model was conceptualized in which security of attachment representations mediated the main-effect of institutionalization on problem behaviours.

\section{METHOD}

\section{Participants}

Participants were 91 Portuguese children, $48 \%$ girls, aged 48-96 months ( $\mathrm{M}=73.4$; standard deviation $[\mathrm{SD}]=10.5)$. There were three different groups: 19 children were institutionalized, 16 children were from low educational level families and 56 children were from high educational level families. Data from the first two groups were collected in the context of two Master Theses. Data of the last group 
came from a larger study on attachment and social development. The constitution of the groups was as follows: Institutionalized: $58 \%$ boys aged between $48-96$ months $(\mathrm{M}=69,2 ; \mathrm{SD}=14,9)$; Low educational level: $31 \%$ girls, aged between 56-85 months $(\mathrm{M}=68,9$; $\mathrm{SD}=9,6)$; High educational level: 50\% boys, aged between 65 and 91 months $(\mathrm{M}=76,2$ : $\mathrm{SD}=7,8)$.

In the institutionalized group, $80 \%$ of the mothers and $100 \%$ of the fathers had less than university education, in low-status families, $81.4 \%$ of the mothers and $69.3 \%$ of the fathers had less than university. In high-status families, only $33.3 \%$ of the mother's and $43.6 \%$ had less than university education.

There were no significant differences in gender between the three groups. As to age, the high educational status children were in average 7 months older than the institutionalized and 7.3 months older than the low-status families and these differences were statistically significant $(\mathrm{F}[2,89]=5,52 ; p<0.05)$. There were no significant differences in age between the institutionalized and the low-educational family-raised children and parent's educational level was equivalent in the two groups.

Separation of the institutionalized children from their families occurred when the children were between 25 and 84 months $(M=54,6 ; S D=17,2)$ and, at the time of data collection, the period of settlement in an institutionalized setting ranged between 2 and 20 months $(\mathrm{M}=8,3$; $\mathrm{SD}=$ $5,5)$. Unfortunately, due to institutional restrictions, it was not possible to collect accurate information regarding the type of situation that led Portuguese Youth Protection Committee to determine children's removal from home, neither regarding the regime of contacts that are still, or not, maintained with the biological parents, what we acknowledged to be an important limitation of this study. Another relevant information that is lacking comprises the quality of care offered by the two institutions that accepted to participate in this study, namely the staff's training and emotional closeness to the children, as well about the rearing philosophy and style of discipline generally adopted.

\section{Instruments}

\section{Attachment Story Completion Task (ASCT)}

Stories were collected by two graduate students after receiving training from two research members with large experience in the application procedure including its videotape recording. Narratives from family-raised groups were collected while children were at school, normally during lunch break, in an empty classroom. In the case of institutionalized children narratives were collected in a withdrawn room within the institutions, after two previous play sessions had taken place with the aim of familiarizing the children with the interviewers. All stories were rated by two blind independent-trained coders, on an eight-point scale for Security, developed by Maia, Ferreira, Silva, Fernandes, and Veríssimo (2009). This scale was inspired by Heller's (2000) work who, based on preexistent contributions (Golby, Bretherton, Winn, \& Page 1995; Page \& Bretherton, 1993; Robinson, Mantz-Simmons, Macfies, \& The MacArthur Narrative Working Group, 1992) proposed a quite comprehensive coding system which included identification of general and summary themes (e.g., prosocial, obedience/discipline, aggression, danger etc.), a broader assessment of narrative aspects (e.g., parental representations, type of story resolution) and performative relevant elements (e.g., overall emotional expressiveness, emotional knowledge, interaction with the interviewer, non-verbal behaviour, investment in performance, fluency and avoidance), together with coherence and security scales. The Security score is a broad parameter which considers plot coherence and the extension to which each attachment-related challenge is acknowledged and successfully dealt with by the child, derived after a global evaluation of the narrative and of the performance at the task is done. Comparing a sub-set of MSSB stories from middle-class and from disadvantaged, Head-Start attendants', pre-scholars Heller (2000) reported that security scores were significantly associated to maternal sensitivity/elaborative style during motherchild talks about past events and to the quality of the mother-child narrative co-construction around a separation-reunion theme. On their turn, secure and coherent attachment story resolutions were predicted by precedent observational measures of child-mother attachment.

In previous works (Maia, Ferreira, Veríssimo, Santos, \& Shin, 2008), trough the integration of recent contributions (e.g., Glogger-Tippelt et al., 2002; Gullón-Rivera \& Bretherton, 2003), we had expanded this Security Scale, by including specific indications for the attribution of type of story resolution to each of the 5 ASCT stories. Susceptible to be identified as indicative of disorganized attachment representations, lower scores $(<2,5)$ are given to incomprehensible, incoherent narratives, that include sequences of disconnected, incongruent, violent and/or bizarre events, or that markedly display avoidance of attachment related issues generally without acknowledgment of story conflicts. When acknowledged, these are not properly solved or, if any type of positive solution is given, it is frequently followed by a negative, dramatic twist with abrupt shifts in the narrative emotional tone. Parents are frequently represented as inept, harsh, neglecting or rejecting towards children, sometimes with enactments of role-reversed interactions, or are unexpectedly absent from the child's discourse. Non verbal behaviour can be characterized by motor agitation and by the display of intense, inappropriate emotions, with the individuals possibly attempting to control the application procedure or, conversely, by a striking emotional inexpressiveness that in the limit may assume a withdraw posture. 
$N$. Torres et al.

Presumably reflecting secure attachment representations, higher values $(>5)$ are given to reasoned scripts, in which attachment related problems are fully acknowledged and positively and creatively solved, reflecting a deeper understanding of the relational and emotional aspects involved.

Stories often integrate both positive and negative elements, but endings always portray a coherent return to harmonious normal interactions among family members with parental figures presenting caring and supportive attitudes. Individuals invest in the task with fluency, spontaneity and pleasure displaying a rich repertoire of emotions. Medium values (between 2.5 and 5) are supposed to represent highly to slight insecure attachment representations describing somewhat incoherent stories, in which attachment-related conflicts are either relatively dealt with, although mainly through functional solutions, or substantially ignored. Narratives tend to be to short and encouragements by the researcher to proceed the narrative may be needed, or there are moderate deviations or contradictions. Some emotional knowledge is present but speech lacks fluency and the investment in the task is quite limited with individuals possibly showing reluctance or difficulties in controlling the expression of emotions.

Inter-observer reliability was assessed through intraclass correlation, and all five narratives showed strong significant coefficients, ranging from 0.78 to 0.93 . The five narratives' scores presented also good internal consistency in the three groups of children (Cronbach's alpha 0.86 to 0.90 ) and were aggregated by calculating their arithmetic mean in a global security score.

\section{Problem Behaviours}

Following a cross-informant model, the Child Behaviour Checklist (CBCL) created by Achenbach in 1991 assesses problem behaviours and competencies of children, being applicable on a large age range (4 to 18 years). In the 6-11 years old version, there are 120 items concerning problem behaviours which can be rated on a three-point Likert scale- 0 'not true', 1 'somewhat or sometimes true' and 2 'very true or often true'. Due to the time constraints imposed by the institutions', boards we used a shortened version consisting of three of the CBCL syndrome scales: Aggressive behaviour, Social Withdrawal and Hyperactivity. The Portuguese version of the CBCL, including the individual syndrome scales have been previously validated by Fonseca, Simões, Rebelo, Ferreira, and Cardoso (1994), in a sample of 1332 Portuguese children. The Cronbach's alpha of the syndrome scales was 0.83 for Aggressive behaviour, 0.77 for Hyperactivity and 0.66 for Social withdrawal.

In the present study, the problem behaviours were reported by the children's mothers (low- and higheducational family-raised children) or main caretakers', previously indicated by the institution's coordinators. In all cases, the questionnaire was filled out by the respondents alone, in the same week the ASCT was applied to the children.

\section{Verbal Competence}

To control for possible confounding effects on narratives due to differential language competence, verbal skills were assessed using the verbal subtests of the Revised Wechsler Preschool and Primary Scale of Intelligence (Wechsler, 1989) in the Portuguese Version (Seabra-Santos et al., 2003). As the objective of using this measure was to obtain a comparable score of language competence for all subjects and not to determine the standardized intelligence quotient score, raw scores of the verbal subtests allowed comparisons of preschool and school children in the sample with a total averaged measure of all verbal sub-tests being derived (Cronbach's alpha $=0.87$ ).

\section{RESULTS}

\section{Attachment Representations and Raising Environment}

ASCT security scores in the three groups proved to be independent of verbal skills, age and educational level of the father and the mother, since all correlation coefficients between security scores and these variables were small and not statistically significant A two-way analysis of variance was performed, with Group and Gender as independent factors and the attachment security score of the ASCT narratives as the dependent variable. Results showed that there was a significant effect of Group on security scores $\left(F[2,90]=8,96 ; p<0.0001 ; \eta^{2}=0.16\right)$ the post hoc tests showed significant differences between the institutionalized group $(\mathrm{M}=4.2 ; \mathrm{SD}=0.25)$ and the two other groups, the low-educational status group $(\mathrm{M}=5.36 ; \mathrm{SD}=$ $0,28)$ and the high-educational status $(M=5.40 ; S D=0.14)$. The post hoc tests showed no significant differences between the two groups of children living with their families. Results also showed a marginally significant effect of gender $\left(F[1,90]=3,72 ; p=0.057 ; \eta^{2}=0.03\right)$ on the attachment security scores. There was no significant effect of the interaction Group $\times$ Gender on the security scores.

Additionally, a categorical classification of security/ insecurity was also derived, using the cut point $>5$ of the security scale continuum score. A categorical classification for disorganized narratives was also derived, using the cut-off point $<2,5$ of the security scale. A Chi-squared test revealed significant differences in the percentage of secure, insecure and disorganized narratives in the three groups of children $\left(\chi^{2}=26,24 ; p<0.0001\right)$. These results are presented in the Table 1.

Further Chi-squared tests showed that there was no significant difference between the children living in low- 
Table 1. Percentage of disorganized, insecure and secure narratives in the three groups of children

\begin{tabular}{lcccr}
\hline & $\begin{array}{c}\text { Institution } \\
(N=19)\end{array}$ & $\begin{array}{c}\text { Low-educational level } \\
\text { families }(N=16)\end{array}$ & $\begin{array}{c}\text { High-educational level } \\
\text { families }(N=56)\end{array}$ & $\begin{array}{r}\text { Total } \\
(N=90)\end{array}$ \\
\hline Disorganized $(\%)$ & $15.8 \%$ & $0 \%$ & $5.5 \%$ & $6.7 \%$ \\
Insecure $(\%)$ & $78 \%$ & $18.9 \%$ & $29.1 \%$ & $37.8 \%$ \\
Secure $(\%)$ & $5.3 \%$ & $81.3 \%$ & $65.5 \%$ & $55.6 \%$ \\
\hline
\end{tabular}

$p<0.001 \cdot \chi^{2}=26.24$.

Table 2. Correlations between security, Verbal competence and Behaviour Problems

\begin{tabular}{|c|c|c|c|c|c|}
\hline & $\begin{array}{c}\text { Verbal } \\
\text { competence }\end{array}$ & Security & Hyperactivity & $\begin{array}{l}\text { Aggressive } \\
\text { behaviour }\end{array}$ & $\begin{array}{c}\text { Social } \\
\text { withdrawal }\end{array}$ \\
\hline Institutionalized & $-0.38^{*}$ & $-0.57^{* *}$ & -0.12 & $0.36^{*}$ & 0.16 \\
\hline Verbal competence & & 0.01 & 0.07 & 0.16 & 0.14 \\
\hline Security & & & -0.32 & $-0.69^{* *}$ & $-0.45^{*}$ \\
\hline Hyperactivity & & & & $0.56^{* *}$ & 0.34 \\
\hline Aggressive behaviour & & & & & 0.28 \\
\hline
\end{tabular}

or high-educational status families, and that there was a significant difference $\left(\chi^{2}=24,78 ; p<0.0001\right)$ between children living in institutions versus children living with their families (when low- and high-educational status were aggregated).

\section{Attachment Representations and Behaviour Problems}

In the subsample comprising the institutionalized children and the low-educational status families' children $(N$ $=35$ ), the relation between institutionalization, behaviour problems and narrative attachment security scores was analysed through regression/correlation analysis, consisting in two steps (1) main effects model or bivariate correlations between the variables in study; and (2) multivariate mediation analysis of indirect effects.

The correlation analyses with the institutionalization variable were made via regression models with dummy coding $(0,1)$ so that children living in an institution received the value 1 and the children living with their families the value 0 (i.e., control group).

\section{Main Effects Model: Zero-Order Bivariate Correlations}

Results presented in Table 2 show that: (1) security scores were significantly negatively correlated with aggressive behaviour and social withdrawal; (2) institutionalized children had higher scores on Aggressive behaviour, lower Verbal skills and lower security scores; (3) hyperactivity is correlated with Aggressive behaviour; and (4) security scores were independent of Verbal skills. In other words, the institutionalized status of children directly predicts low security ratings of ASCT responses, high aggressive behaviour scores and low verbal scores.
Table 3. Mediation model summary

\begin{tabular}{lcccc}
\hline \multicolumn{5}{l}{ Dependent variable: aggressive behaviour } \\
\hline Predictor & Beta & R2 & R2 change & F change \\
\hline $\begin{array}{l}\text { Step1 } \\
\quad \text { Institutionalization }\end{array}$ & $0.36^{*}$ & & & \\
& & 0.13 & 0.13 & 3.16 \\
$\begin{array}{l}\text { Step2 } \\
\quad \text { Institutionalization }\end{array}$ & -0.05 & & & \\
Attachment Security & $-0.72^{* *}$ & & & \\
& & 0.48 & 0.35 & 13.60 \\
\hline
\end{tabular}

${ }^{*} p<0.05 .{ }^{* *} p<0.01$

Security ratings of ASCT responses, in turn, predict ratings of both aggression and social withdrawal.

Therefore the correlation matrix suggests that for aggressive behaviour, a mediation role of attachment representations might be more adequate to explain the link between institutionalization and problem behaviour.

\section{Mediation Analysis Model}

Following the procedures of Baron and Kenny (1986) and Preacher and Hayes (2004), results showed that the effect of institutionalization on aggressive behaviour is fully mediated by the security scores of attachment narratives. The first step of the mediation model was presented in the main effects model above: the variables Institutionalization and Security of attachment representations are significantly correlated among them and are also both significantly correlated with aggressive behaviour.

Finally, as can be seen in the Table 3, the effect of Institutionalization on Aggressive behaviour (Step 1 of 


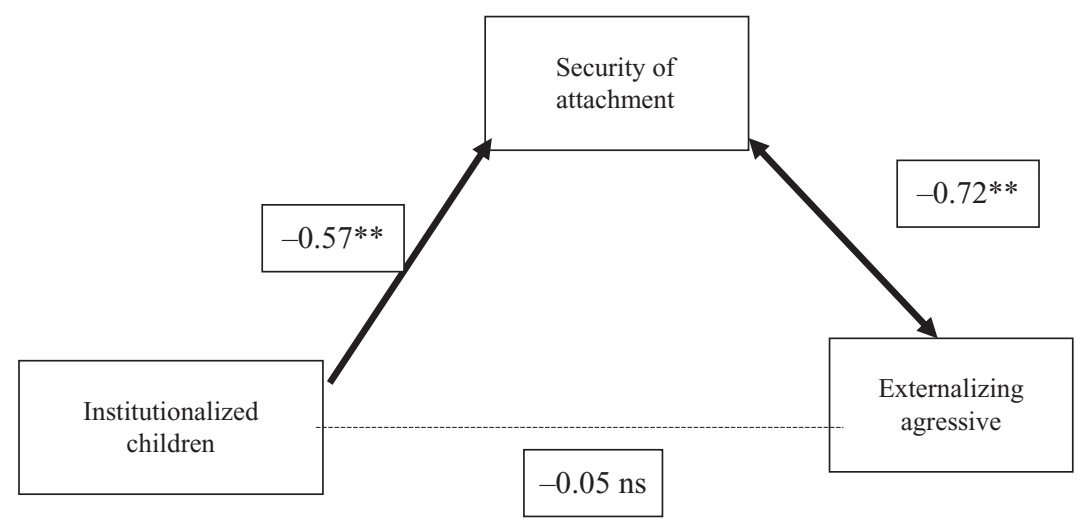

Figure 1. Indirect effects: mediation model of attachment internal model security. ${ }^{* *} 0.01$. ns $=$ not significant

the model) is reduced to virtually zero when the security of the attachment narratives is entered in the model (Step 2). In contrast, the association of security of attachment representations with aggressive behaviour remains even after controlling for Group (Step 2). Hence, the effect of Institutionalization on Aggressive behaviour is completely mediated by the security of the attachment representations (see Figure 1). Analysis of the significance of the indirect effects using the two paths of the mediation model simultaneously revealed statistically significant results $(t=3,14 ; p<0.01)$ in three different tests: Sobel test, Aroian test and the Goodman test.

\section{DISCUSSION}

In support the thesis that the absence of a 'good enough' raising environment accompanied by disruptions in early emotional bonds makes it more difficult for children to organize secure attachment representations, in consonance with our first hypothesis, in average, the institutionalized group, even after differences in verbal skills were controlled, has produced narratives with lower security scores. Besides, in some narratives from this group was found a noteworthy presence of intra-family violent interactions, severe disasters and sudden deaths, together with enactments of role-reversed parents-child relationships and sometimes even explicit sexual contents. In line with what was presented before, we believe this features possibly reflect children's attempts to deal either with heavy real experiences from the past, either, symbolically, with fears and uncertainties from the present (e.g., not knowing where parents are or when are they going to see them again or till when will they stay at the present institution).

Contrarily to what we had supposed, there were no differences between the two family-raised groups, what may be justifiable by the fact that, apart for divergences in parents' years of education, no other risk factors where known to exist in the low-educational level group. In fact, the inexistence of additional information regarding others family conditions (e.g., parental unemployment, health problems, economic constraints, perceived stress, degree of involvement in child-care activities) is another limitation of the present study.

As predicted, by comparison with family-raised children with equivalent low-educational status, institutionalized children showed higher scores on Aggressive behaviour. However, no discrepancies between groups were found regarding the Hyperactivity and Social Withdrawal scales. Congruently, with our forecast, independently from the raising environment status, security scores were negatively correlated with aggressive behaviour and social withdrawal, although not with hyperactivity. Finally, support was found for the initial conceptualization of a mediation model in which security of attachment representations mediates the main-effect of institutionalization on aggressive behaviour.

Research has been suggesting that during childhood, problematic behaviours might be substantially conceived in terms of difficulties in attachment-caregiving interactions, specially, as pointed out by Marvin (2009), when the caregiving context persistently ignores, rejects or misunderstands the child's attachment behaviours without decreasing the child's distress and level of arousal (see Fearon, Bakermans-Kranenburg, van IJzendoorn, Lapsley, \& Roisman, 2010; Deklyen \& Greenberg, 2008). Not having available, sensitive and responsive adults to whom to ask for help and comfort, when facing frightening situations, the insecure child has to deal with the adverse experience simultaneously with her own hyper-aroused attachment system by herself, experiencing higher levels of internal anxiety. Besides, it is also known that with the aim of eliciting unequivocal attention and proximity from adults, insecure children may use behavioural strategies 
that often lead to the minimization or exaggeration of the attachment behaviour (see Kobak \& Madsen (2008) discussion on Ainsworth, Blehar, Waters, \& Wall (1978) and Bowlby's (1973, 1980, 1982, 1988) theoretical propositions regarding the organization of insecure strategies).

If, as Bowlby (1973) pointed out, under extreme stress situations anxiety, as well as fear, anger and sadness have been identified as natural adaptive responses to attachment-related threats, the persistence of these emotional states over time can contribute to the maintenance of a hyper-alerted internal state fostering a behavioural prototype that, in time, may give place to symptomatic aggressive behaviour. Following this line, it is important to pay attention to the significant associations found between the aggressive and the hyperactive syndrome scales.

On the other hand, it's also been acknowledged that insecure attachment representations are often associated to a range of bad expectations about the self (e.g., Cassidy, 1988; Maia, et al., 2008; Verschueren et al., 1996), experienced as undesired and unworthy what may lead the individual to make frequent erroneous generalizations about others' negative intents. In addition, insecure children are expected to carry a very rudimentary understanding of the give-and-take of close interactions, and to lack a sense of self-worth and efficacy, becoming more difficult for them to have confidence in the active, and socially competent, exploration of new relational contexts (e.g., Bost, Vaughn, Washington, Cielinski, \& Bradbard, 1998). Social withdrawal or aggressiveness, therefore, can possibly be viewed as two possible, although opposite, 'justifiable' answers and attempts to cope with a social world that is perceived as hostile, rejecting or abusive.

The fact that the security of attachment representations fully mediates the link between the institutional rearing condition and the manifestation of aggressive behaviour, underpins both the necessity of detecting, and making action against, parental abusive and/or negligent practices and the multi-challenges, detailed by Dozier and Rutter (2008), that institutional care brings for children's attachment security and, consequently, mental health quality and social adjustment.

Moreover, our findings support the notion that secure representations can be protective factors that contribute to the child's resilience even in the presence of adverse co-ocurrent conditions. Unfortunately, the small number of institutionalized children was not sufficient to arrive to definitive conclusions regarding what may have facilitated some of the institutionalized children to perform in the ASCT in ways that allowed high security ratings. Indeed, a deterministic point of view should be refused, with attachment theory (Bowlby, 1973) supporting the notion of representations' dynamism, as they can eventually be reshaped through the life course by the integration of posterior relevant relational experiences (e.g., well succeed adoption, establishment of good friendships later on). To sum up, this exploratory study hopes to bring attention to the importance of offering to children separated from their families a predictable and safe caregiving context that is able to persist in time and encompasses protective, stable and strong attachment relationships, as well as opportunities for exploration and mastery of the world. Being an essential condition to promote the recovery from neglect and abusive experiences, this seems to be the only key that enables change in representations and consequently, in problematic behaviours.

\section{ACKNOWLEDGMENTS}

The authors wish to thank all the children, families and institutions who participate in this study. This work was supported in part by grant $\mathrm{s}$ from FCT (PTDC/ PSI/64149/2006). We are also grateful to all the colleagues from Line 1 of UIPCDE - Developmental Psychology for their valuable comments. A Special word to Joana Pinhel, Barbara Ramos to their help on data collection. Finally, our deepest gratitude to Inge Bretherton not only for her insightful comments, but specially for being such an inspiration both personally and scientifically.

\section{REFERENCES}

Ainsworth, M., Blehar, M., Waters, E., \& Wall, S. (1978). Patterns of attachment: A psychological study of the strange situation. Oxford England: Lawrence Erlbaum.

Bakermans-Kranenburg, M., van IJzendoorn, M., \& Juffer, F. (2008). Earlier is better: A meta-analysis of 70 years of intervention improving cognitive development in institutionalized children. Monographs of the Society for Research in Child Development, 73(3), 279-293.

Baron, R.M., \& Kenny, D.A. (1986). The moderator-mediator variable distinction in social psychological research: Conceptual, strategic and statistical considerations. Journal of Personality and Social Psychology, 51, 1173-1182.

Bost, K.K., Vaughn, B.E., Washington, W., Cielinski, K., \& Bradbard, M. (1998). Social competence, social support and attachment: Demarcation of construct domains, measurement, and paths of influence for preschool children attending Head Start. Child Development, 69, 192-218.

Bowlby, J. (1944). Forty-four juvenile thieves: Their characters and home lives. International Journal of Psycho-Analysis, 25, 19-52.

Bowlby, J. (1951) Maternal care and mental health. WHO Monograph 2. Geneva: World Health Organization.

Bowlby, J. (1973). Attachment and loss: Vol. 2 Separation, anxiety, and anger. New York: Basic Books.

Bowlby, J. (1980). Attachment and loss: Vol. 3. Loss. New York: Basic Books.

Bowlby, J. (1982). Attachment and loss: Vol.1. Attachment (2nd rev. ed.) New York: Basic Books (Original work published, 1969). Journal, 11(3), 237-252.

Bowlby, J. (1988). A secure base. Parent-child attachment and healthy development. New York: Basic Books. 
Bretherton, I. (1990). Communication patterns, internal working models, and the intergenerational transmission of attachment relationships. Infant Mental Health Journal, 11(3), 237-252.

Bretherton, I. (2005). In pursuit of the internal working model construct and its relevance to attachment relationships. In K.E. Grossmann, K. Grossmann, E. Waters, E. Klaus (Ed.), Attachment from infancy to adulthood: The major longitudinal studies (pp. 13-47). New York, NY: Guilford Publications.

Bretherton, I., \& Ridgeway, D. (1990). Story completion task to assess children's internal working model of child and parent in the attachment relationship. In M.T. Greenberg, D. Cicchetti, E.M. Cummings (Eds.), Attachment in the preschool years. Theory, research and intervention (pp. 300-305). Chicago: The University of Chicago Press.

Bretherton, I., Biringen, Z., Ridgeway, D., Maslin, C., \& Sherman, M. (1989). Attachment: the parental perspective. Infant Mental Health Journal, 10(3), 203-221.

Bretherton, I., Oppenheim, D., Buchsbaum, H., \& Emde, R.N. (1990). The MacArthur story stem battery. Unpublished manuscript, University of Wisconsin-Madison. Published 2003 In R.N. Emde, D.P. Wolf, D. Oppenheim (Eds.), Revealing the inner worlds of young children: The MacArthur story stem battery and parentchild narratives (pp. 381-396). New York: Oxford University Press.

Bretherton, I., Ridgeway, D., \& Cassidy, J. (1990). Assessing internal working models of the attachment relationship. An attachment story completion task for 3-years-old, in M.T. Greenberg, D. Cicchetti, E.M. Cummings (Eds.), Attachment in the preschool years. Theory, research and intervention (pp. 273-308). Chicago: The University of Chicago Press.

Cassibba, R., Coppola, G., \& Bruno, S. (2003). Analisi preliminari per la validazione dell'Atttachment story completion task e dell'Attachment Q-sort. Psicologia Clinica dello Sviluppo, 7(3), 407-455.

Cassidy, J. (1988). Child mother attachment and the self in 6-year olds. Child Development, 59, 121-134.

Chisholm, K. (1998). A 3-year follow-up of attachment and indiscriminate friendliness in children adopted from Romanian orphanages. Child Development, 69, 1092-1106.

Ciccheti, D., \& Valentino, K. (2006). An ecological transactional perspective on child maltreatment: Failure of the average expectable environment and its influence on child development. In D. Cicchetti, D.J. Cohen (Eds.), Developmental psychopathology. Volume I. Theory and methods (2nd ed., pp. 129-201). New York: John Wiley \& Sons.

Deklyen, M., \& Greenberg, M. (2008). Attachment and psychopathology in childhood. In J. Cassidy, P.R. Shaver (Eds.), Handbook of attachment: Theory, research, and clinical applications (2nd ed., pp. 637-665). New York, NY: Guilford Press.

Dozier, M., \& Rutter, M. (2008). Challenges to the development of attachment relationships faced by young children in foster and adoptive care. In J. Cassidy, P.R. Shaver (Eds.), Handbook of attachment: Theory, research, and clinical applications (2nd ed. pp. 698-717). New York, NY: Guilford Press.

Emde, R. (2003). Early narratives: a window to the child's inner world. In R. Emde, D. Wolf, D. Oppenheim (Eds.). Revealing the inner worlds of young children-the MacArthur story stem battery and parent-child narratives (pp. 3-26). New York: Oxford University Press.

Fearon, R., Bakermans-Kranenburg, M., van IJzendoorn, M., Lapsley, A., \& Roisman, G. (2010). The significance of insecure attachment and disorganization in the development of children's externalizing behavior: A meta-analytic study. Child Development, 81(2), 435-456.

Fonseca, A.C., Simões, A., Rebelo, J.A., Ferreira, J.A.A., \& Cardoso, F. (1994). Um inventário de competências sociais e de problemas de comportamento em crianças e adolescentes. $\mathrm{O}$ Child Behaviour Checklist de Achenbach (CBCL). Psychologica, 12, 55-78.

George, C., Kaplan, N., \& Main, M. (1984). The Berkeley Adult Attachment Interview. Unpublished manuscript, University of California at Berkeley.

Gloger-Tippelt, G., Gomille, B., König, L., \& Vetter, J. (2002). Attachment representations in 6-year-olds: Related longitudinally to the quality of attachment in infancy and mothers' attachment representations. Attachment \& Human Development, 4(3), 318-339.

Golby, B., Bretherton, I., Winn, L., \& Page, T. (1995). Coding manual for the Attachment Story Completion Task. Unpublished manuscript, University of Wisconsin-Madison.

Goldwyn, R., Stanley, C., Smith, V., \& Green, J. (2000). The Manchester Child Attachment Story Task: relationship with parental AAI, SAT and child behaviour. Attachment $\mathcal{E}$ Human Development, 2(1), 71-84.

Goodman, G., Aber, J., Berlin, L., \& Brooks-Gunn, J. (1998). The relations between maternal behaviors and urban preschool children's internal working models of attachment security. Infant Mental Health Journal, 19(4), 378-393.

Green, J., Stanley, C., Smith, V., \& Goldwyn, R. (2000). A new method of evaluating attachment representations in young school-age children: The Manchester Child Attachment Story Task. Attachment \& Human Development, 2(1), 48-70.

Gullon-Rivera, A. \& Bretherton, I. (2003). Classification system for self-representations reflected in responses to the Attachment Story Completion Task. Unpublished manuscript. University of Wisconsin-Madison.

Heller, C. (2000). Attachment and social competence in preschool children. Master's thesis. Unpublished manuscript, Auburn University, AL.

Hubbs-Tait, L., Hughes, K., Culp, A., Osofsky, J., Hann, D., Eberhart-Wright, A., \& Ware (1996). Children of adolescent mothers: Attachment representation, maternal depression, and later behavior problems. American Journal of Orthopsychiatry, 66(3), 416-426.

Katsurada, E. (2007). Attachment representation of institutionalized children in Japan. School Psychology International, 28(3), 331-345.

von Klitzing, K., Kelsay, K., Emde, R., Robinson, J., \& Schmitz, S. (2000). Gender-specific characteristics of 5-year-olds' play narratives and associations with behavior ratings. Journal of the American Academy of Child \& Adolescent Psychiatry, 39(8), 1017-1023.

Kobak, R., \& Madsen, S.D. (2008). The emotional dynamics of disruptions in attachment relationships: Implications for theory, research, and clinical intervention. In J. Cassidy, P.R. Shaver (Eds.), Handbook of attachment (pp. 23-47. New York, NY: Guilford Press.

Kobak, R.; Cassidy, J. Lyons-Ruth, K., \& Ziv, Y. (2006) Attachment, stress, and psychopathology: A developmental pathways model. In D. Cicchetti, D.J. Cohen, (Eds.), Developmental psychopathology. Volume I. Theory and methods (2nd ed., pp. 333-369). New York: John Wiley \& Sons.

Laible, D., Carlo, G., Torquati, J., \& Ontai, L. (2004). Children's perceptions of family relationships as assessed in a doll story completion task: Links to parenting, social competence, 
and externalizing behavior. Social Development, 13(4), 551569.

MacLean, K. (2003). The impact of institutionalization on child development. Development and Psychopathology, 15(4), 853884.

Maia, J., Ferreira, B., Silva, F., Fernandes, M., \& Veríssimo, M. (2009). Adaptação portuguesa do AttachmentStory Completion Task-manual de aplicação e cotação: Dimensão Contínua de Segurança. Manuscrito não publicado. Instituto Superior de Psicologia Aplicada, Lisboa.

Maia, J., Ferreira, B., Veríssimo, M., Santos, A.J., \& Shin, N. (2008). Auto-conceito e representações da vinculação no período pré-escolar. Análise Psicológica, 3(26), 423-433.

Main, M., Kaplan, N., \& Cassidy, J. (1985). Security in infancy, childhood, and adulthood: a move to the level of representation. Monographs of the Society for Research in Child Development, 50(1/2), 66-104.

Marvin, R. (2009). Defiant and disruptive child behavior problems: a view from the 'Circle of Security'. In K.H. Brisch, T. Hellbrugge (Eds.), Wege zu sicheren Bindugen in Familie und Gesellschaft. Pravention, Begleitung, Beratung und Psychotherapie (pp.187-212). Stuttgart: Klett-Cotta.

Miljkovitch, R., Pierrehumbert, B., \& Halfon, O. (2007). Threeyear-olds' attachment play narratives and their associations with internalizing problems. Clinical Psychology E Psychotherapy, 14(4), 249-257.

Miljkovitch, R., Pierrehumbert, B., Bretherton, I., \& Halfon, O. (2004). Associations between parental and child attachment representations. Attachment \& Human Development, 6(3), 305325. doi:10.1080/14616730412331281557.

O'Connor, T., Bredenkamp, D., \& Rutter, M. (1999). Attachment disturbances and disorders in children exposed to early severe deprivation. Infant Mental Health Journal, 20(1), 1029.

Oppenheim, D. (1997). The Attachment Doll-play Interview for preschoolers. International Journal of Behavioral Development, 20(4), 681-697. doi:10.1080/016502597385126.

Oppenheim, D. (2003). Children's emotional resolution of MSSB narratives: Relations with child behaviour problems and parental psychological distress. In R.N. Emde, D.P. Wolf, D. Oppenheim (Eds.), Revealing the inner worlds of young children: The MacArthur Story Stem Battery and parent-child narratives (pp. 147-162). New York, NY: Oxford University Press.

Oppenheim, D., \& Waters, H.S. (1995). Narrative processes and attachment representations: Issues of development an assessment. In E. Waters, B.E. Vaughn, G. Posada, K. Kondo-Ikemura (Eds.), Caregiving, cultural, and cognitive perspectives on secure-base behaviour and working models: New growing points of attachment theory and research (pp. 197-215). New York: Wiley-Blackwell. Monographs of Society for Research in Child Development, 60.

Oppenheim, D., Nir, A., Warren, S., \& Emde, R. (1997). Emotion regulation in mother-child narrative co-construction: Associations with children's narratives and adaptation. Developmental Psychology, 33(2), 284-294.

Page, T., \& Bretherton, I. (1993). Manual for coding the expanded attachment story completion task. Unpublished manuscript, University of Wisconsin-Madison.

Page, T., \& Bretherton, I. (2001). Mother- and father-child attachment themes in the story completions of pre-schoolers from post-divorce families: Do they predict relationships with peers and teachers? Attachment and Human Development, 3, 1-29.

Page, T., \& Bretherton, I. (2003). Representations of attachment to father in the narratives of preschool girls in post-divorce families: Implications for family relationships and social development. Child \& Adolescent Social Work Journal, 20(2), 99-122.

Pierrehumbert, B., Santelices, M., Ibáñez, M., Alberdi, M., Ongari, B., \& Roskam, I.(2009). Gender and attachment representations in the preschool years: Comparisons between five countries. Journal of Cross-Cultural Psychology, 40(4), 543566.

Poehlmann, J. (2005). Representations of attachment relationships in children of incarcerated mothers. Child Development, 76(3), 679-696. doi:10.1111/j.1467-8624.2005.00871.x.

Preacher, K., \& Hayes, A. (2004) SPSS and SAS procedures for estimating indirect effects in simple mediation models. Behavior Research Methods, Instruments and Computers, 36, 717-731.

Radke-Yarrow, M., McCann, K., DeMulder, E., \& Belmont, B. (1995). Attachment in the context of high-risk conditions. Development and Psychopathology, 7(2), 247-265.

Robinson, J., Mantz-Simmons, L., Macfie, J., \& The MacArthur Narrative Working Group (1992). The Narrative Coding Manual. Unpublished manuscript, University of Colorado, Boulder.

Rutter, M., Colvert, E., Kreppner, J., Beckett, C., Castle, J., \& Groothues, C. (2007). 'Early adolescent outcomes for institutionally deprived and non-deprived adoptees. I: Disinhibited attachment': Erratum. Journal of Child Psychology and Psychiatry, 48(8), 17-30.

Seabra-Santos, M.J., Simões, M.R., Albuquerque, C.P., Pereira, M.M., Almeida, L.S., Ferreira, C., Lança, C., \& Lopes, A.F. (2003). Escala de Inteligência de Wechsler para a Idade PréEscolar e Primária-Forma Revista (WPPSI-R.). In M.M. Gonçalves, M.R. Simões, L.S. Almeida, C. Machado (Coords.), Avaliação psicológica: Instrumentos validados para a população (Vol. I, pp. 197-219). Coimbra: Quarteto.

Silva, F., Fernandes, M., Veríssimo, M., Shin, N., Vaughn, B.E., \& Bost, K.K. (2008). A concordância entre o comportamento de base segura com a mãe nos primeiros anos de vida e os modelos internos dinâmicos no pré-escolar. Análise Psicológica, 3(26), 411-422.

Smeekens, S., Riksen-Walraven, J., \& Van-Bakel, H. (2009). The predictive value of different infant attachment measures for socioemotional development at age 5 years. Infant Mental Health Journal, 30(4), 366-383. doi:10.1002/imhj.20219.

Smyke A.T., Dumitrescu A, Zeanah C.H. (2002). Attachment disturbances in young children. I: The continuum of caretaking casualty. Journal of the American Academy of Child and Adolescent Psychiatry, 41(8), 972-982.

Smyke, A.T., Koga, S.F., Johnson, D.E., Fox, N.A., Marshall, P.J., Nelson, C.A., \& Zeanah, C.H. (2007). The caregiving context in institution-reared and family-reared infants and toddlers in Romania. Journal of Child Psychology \& Psychiatry, 48(2), 210-218.

Solomon, J., George, C., \& DeJong, A. (1995). Children classified as controlling at age six: Evidence of disorganized representational strategies and aggression at home and at school. Development and Psychopathology, 7(3), 447-463.

Sroufe, L.A., Egeland, B.E., Carlson, E.A., \& Collins, W.A. (2005). Placing early attachment experiences in developmental context: The Minnesota longitudinal study. In K.E. Grossmann, K. Grossmann, E. Waters (Eds.) Attachment from infancy to adulthood. The major longitudinal studies (pp.44-70). New York: The Guilford Press.

Tizard, B., \& Rees, J. (1975). The effect of early institutional rearing on the behaviour problems and affectional 
relationship of 4-year-old children. Journal of Child Psychology $\mathcal{E}$ Psychiatry \& Allied Disciplines, 16(1), 61-73.

Toth, S., Cicchetti, D., Macfie, J., Rogosch, F., \& Maughan, A. (2000). Narrative representations of moral-affiliative and conflictual themes and behavioral problems in maltreated preschoolers. Journal of Clinical Child Psychology, 29(3), 307-318.

Trapolini, T., Ungerer, J., \& McMahon, C. (2007). Maternal depression and children's attachment representations during the preschool years. British Journal of Developmental Psychology, 25(2), 247-261.

Verschueren, K., \& Marcoen, A. (1999). Representation of self and socioemotional competence in kindergartners: Differential and combined. Child Development, 70(1), 183-201.

Verschueren, K., Marcoen, A., \& Schoefs, V. (1996). The internal working model of the self, attachment, and competence in 5-year-olds. Child Development, 67(5), 2493-2511. doi:10.2307/1131636.

Vorria, P., Papaligoura, Z., Sarafidou, J., Kopakaki, M., Dunn, J., \& Van IJzendoorn, M., (2006). The development of adopted children after institutional care: a follow-up study. Journal of Child Psychology \& Psychiatry, 47(12), 1246-1253.

Warren, S. (2003). Narratives in risk and clinical populations. In R. Emde, D. Wolf, D. Oppenheim (Eds.), Revealing the inner worlds of young children- the MacArthur story stem battery and parent-child narratives (pp. 222-239). New York: Oxford University Press.
Waters, E., \& Crowell, J.A. (1999). Atypical attachments in atypical circumstances: A commentary. In J.I. Vondra, D. Barnett (Eds.), Atypical attachment in infancy and early childhood among children at developmental risk, Monographs of the Society for Research in Child Development, 64 (3, Serial no. 258), 213220.

Waters, H.S., Rodrigues, L.M., \& Ridgeway, D. (1998). Cognitive underpinnings of narrative attachment assessment. Journal of Experimental Child Psychology, 71, 211-234.

Wechsler, D., (1989). WPPSI-R-Wechsler Preschool and Primary Scale of Intelligence-Revised. San Antonio: The Psychological Corporation.

Weinfield, N.S., Sroufe, L.A., \& Egeland, B. (2000). Attachment from infancy to early adulthood in a high-risk sample: Continuity, discontinuity, and their correlates. Child Development, 71(3), 695-702.

Zeanah, C.H., \& Smyke, A.T. (2008). Attachment disorders in family and social context. The infant's relational worlds: Family, community \& culture. Infant Mental Health Journal, 29(3), 219-233.

Zeanah, C.H., Egger, H.L., Smyke, A.T., Nelson, C.A., Fox, N.A., \& Marshall, P.J. (2009). Institutional rearing and psychiatric disorders in Romanian preschool children. The American Journal of Psychiatry, 166(7), 777-785.

Zeanah, C.H., Smyke, A.T., \& Dumitrescu, A. (2002). Attachment disturbances in young children: II. Indiscriminate behavior and institutional care. Journal of the American Academy of Child and Adolescent Psychiatry, 41, 983-989. 